\section{WORK CAPACITY AND CENTRAL HEMODYNAMICS THIRTEEN TO TWENTY-SIX YEARS AFTER REPAIR OF TETRALOGY OF FALLOT}

Exercise tests and cardiac catheterization were performed in 53 patients, 13 to 26 years after intracardiac repair of tetralogy of Fallot. At the time of repair, the median age was 7 years, and $60 \%$ of patients with cyanosis had had a previous palliative procedure. The right ventriculotomy was closed without a patch in 21 patients $(40 \%)$, a patch restricted to the right ventricle was inserted in 18 patients (34\%), and in $14(26 \%)$ the patch extended across the pulmonary anulus. At follow-up, 94\% of the patients were free of symptoms. Symptomlimited work capacity was $87 \%$ of the predicted value $(95 \%$ confidence limits, $82 \%$ to $94 \%$ ). Work capacity was inversely related to age at follow-up, to right ventricular systolic pressure at rest, and to presence of moderate or severe pulmonary valve regurgitation. Cardiac output in relation to oxygen uptake was reduced in $74 \%$ of patients during exercise. In 12 patients $(23 \%)$, systolic pressure at rest in the right ventricle was $50 \mathrm{~mm} \mathrm{Hg}$ or higher. Systolic pressure during exercise in the right ventricle was lower in patients without a patch than in those with a patch and was abnormally high in all groups compared with healthy subjects. The ratio of right to left ventricular pressure was significantly lower than measurements taken immediately after repair. An intracardiac left-to-right shunt was present in 6 patients $(11 \%)$. Three patients required invasive treatment as a result of our follow-up. We conclude that work capacity was moderately reduced 13 to 26 years after repair of tetralogy of Fallot and was adversely influenced by right ventricular hypertension and pulmonary valve regurgitation. Intermittent lifelong surveillance is advocated, because patients without symptoms may have hemodynamic abnormalities that necessitate intervention. (J THOraC CARDIOvasc SuRg 1995;110:416-26)

Hans Jonsson, MD, ${ }^{\text {a }}$ Torbjörn Ivert, MD, ${ }^{a}$ Rune Jonasson, MD, ${ }^{b}$ Alf Holmgren, MD, ${ }^{\mathrm{b}}$ and Viking O. Björk, MD, ${ }^{\mathrm{a}}$ Stockholm, Sweden lson ntracardiac repair of tetralogy of Fallot with closure of the ventricular septal defect, resection of the obstructing myocardium, and creation of a sufficiently wide right ventricular outflow tract gives excellent long-term clinical results in more than $70 \%$ of patients. ${ }^{1-5}$ Patients can be free of symptoms after repair but still have residual or recurrent hemodynamic abnormalities, such as an intracardiac shunt, right ventricular aneurysm after patch enlargement, outflow obstruction or pulmonary valve regurgitation, or peripheral pulmonary artery obstruction. ${ }^{1-10} \mathrm{Be}-$

From the Departments of Thoracic Surgery and Clinical Physiology, Thoracic Clinics, Karolinska Hospital, Stockholm, Sweden.

Received for publication July 25, 1994.

Accepted for publication Dec. 30, 1994.

Address for reprints: Torbjörn Ivert, MD, Thoracic Surgical Clinic, Karolinska Hospital, 17176 Stockholm, Sweden.

Copyright (C) 1995 by Mosby-Year Book, Inc.

$0022-5223 / 95 \$ 3.00+0 \quad \mathbf{1 2 / 1 / 6 3 1 8 8}$ cause their presence implies an increased risk of cardiac failure and early death, significant lesions of this kind should be identified and the patient should be considered for reoperation. $2,3,6,11,12$

We performed exercise tests and cardiac catheterization in long-term survivors after repair of tetralogy of Fallot. The aims were to assess work capacity in relation to that predicted, to calculate predictors of work capacity, to analyze central hemodynamics at rest and during exercise in relation to use of an outflow patch, and to identify patients with right ventricular dysfunction and those with a favorable outcome.

\section{Patients and methods}

Patients. A total of 165 consecutive patients with tetralogy of Fallot had intracardiac repair from 1966 through 1976. Twenty-four patients $(15 \%)$ died within 30 days of the operation. Sixteen of the original survivors had died by December 1991. Fifteen patients lived abroad and were lost to follow-up. 
Fifty-three (48\%) of the remaining 110 survivors consented to recatheterization. Clinical variables of these patients at repair did not differ significantly from those of patients not evaluated (Table I). Five patients (9\%) did not have any history of cyanosis before repair. Palliative operations were performed at a median age of 3 years (range, 4 days to 29 years) in 29 of the 48 patients with cyanosis $(60 \%)$. One patient had a Brock procedure, 25 had a Blalock-Taussig anastomosis (left in 17, right in 8), and in 3 a Potts anastomosis was created.

Before intracardiac repair, cardiac catheterization and angiography were performed to assess the diagnosis. All patients had ventriculoarterial concordance, aortic-mitral annular fibrous continuity, malalignment of the infundibular septum causing a large, nonrestrictive ventricular septal defect, and infundibular muscular obstruction of the right ventricular outflow tract. One patient with Down syndrome had an atrioventricular septal defect. Pulmonary annular or valvular obstruction was present in 22 patients $(51 \%)$. One patient had main pulmonary artery atresia. One patient had atresia and two had significant stenosis of the left pulmonary artery. Two patients had a secundum-type atrial septal defect, one had a persisting left superior vena cava, and four patients had a persisting patent ductus arteriosus.

Surgical technique. The operations were performed by means of a median sternotomy with the aid of cardiopulmonary bypass and hypothermia at $28^{\circ}$ to $30^{\circ} \mathrm{C}$. The aorta was intermittently crossclamped for 15 to 20 minutes, and the mean total crossclamp time was 37 minutes, with a $95 \%$ confidence limits (CL) of 32 to 41 minutes. In four patients, circulatory arrest was used for 9 to 63 minutes. A vertical right ventriculotomy was used in all patients to close the ventricular septal defect with a patch of Dacron or Teflon material. In two patients, a left anterior coronary artery that originated from the right coronary artery and crossed the right ventricular outflow tract could be saved.

The outflow of the right ventricle was widened by resecting the parietal extension of the infundibular septum and obstructing trabeculae. The pulmonary valve was dilated with a Hegar probe in two patients (4\%), a commisurotomy was performed in $14(26 \%)$, the valve was totally or partially excised in $15(28 \%)$, and in the remaining 22 patients the annular size and the valve appeared normal.

The decision to insert a patch was made at the time of operation if there was any doubt about achieving an outflow with a lumen at least as large as the diameter of the main pulmonary artery, as measured with Hegar probes. The right ventricular wall was closed directly with interrupted sutures in 21 patients (40\%), with an outflow patch restricted to the right ventricle in 18 patients (34\%), and with a patch that extended across the pulmonary anulus in 14 patients ( $26 \%$ ). In three of the last group, the patch extended onto the left pulmonary artery.

Postrepair systolic pressures were measured in the operating room after discontinuation of the cardiopulmonary bypass. If the postrepair right ventricular/left ventricular (RV/LV) pressure ratio exceeded 0.8 , further widening of the outflow was considered.
Table I. Clinical data at intracardiac repair of tetralogy of Fallot in 53 survivors examined by late catheterization and in 72 survivors not examined*

\begin{tabular}{lccc}
\hline & $\begin{array}{c}\text { Catheterization } \\
(n=53)\end{array}$ & $\begin{array}{c}\text { No } \\
\text { catheterization } \\
(n=72)\end{array}$ & $\begin{array}{c}p \\
\text { Value }\end{array}$ \\
\hline $\begin{array}{l}\text { Female patients } \\
\quad \text { No.) }\end{array}$ & $22(42 \%)$ & $34(47 \%)$ & 0.65 \\
$\begin{array}{c}\text { No outflow } \\
\text { patch (No.) }\end{array}$ & $22(42 \%)$ & $40(56 \%)$ & \\
$\begin{array}{c}\text { Right ventricular } \\
\text { patch (No.) }\end{array}$ & $18(34 \%)$ & $14(19 \%)$ & 0.15 \\
$\begin{array}{c}\text { Transannular } \\
\text { patch (No.) }\end{array}$ & $13(24 \%)$ & $18(25 \%)$ & \\
$\begin{array}{c}\text { Age (yr) } \\
\text { Body surface } \\
\left.\text { area (m }{ }^{2}\right)\end{array}$ & $7(1-42)$ & $7(1-43)$ & 0.57 \\
$\begin{array}{c}\text { Extracorporeal } \\
\text { circulation (min) }\end{array}$ & $90(50-140)$ & $87(49-146)$ & 0.78 \\
$\begin{array}{c}\text { Postrepair RV/LV } \\
\text { pressure ratio }\end{array}$ & $0.51(0.24-1.04)$ & $0.55(0.20-1.00)$ & 0.53 \\
$\quad$ & & $0.9(0.5-2.3)$ & 0.84 \\
\end{tabular}

Median and range (in parentheses) are given for continuous data. $R V / L V$, right ventricular/left ventricular.

*Fifteen were lost to follow-up; 57 did not consent to invasive reevaluation.

Follow-up. The follow-up examinations were conducted between April 1, 1988, and December 31, 1991, a median of 19 years (range, 13-26 years) after intracardiac repair. The study was approved by the committee of ethics at this hospital and the patients' informed consent was obtained. Reoperation had been carried out in three $(6 \%$ ) of the 53 long-term survivors, at 14, 53, and 216 months after repair, because of a residual ventricular septal defect in one and because of right ventricular outflow obstruction in two. ${ }^{13}$

Symptom-limited work capacity in watts $\left(\mathrm{W}_{\mathrm{SL}}\right)$ was assessed with the patient in the sitting position on a bicycle ergometer (Siemens-Elema AB, Stockholm, Sweden) until symptoms such as dyspnea, general fatigue, or leg fatigue caused the patient to stop. Limiting symptoms were rated from 0 to 10 , according to the scale of Borg, Holmgren, and Lindblad. ${ }^{14}$ Normal values for $\mathrm{W}_{S L}$ were calculated from age, sex, and body weight. ${ }^{1.5}$ Percent $\mathrm{W}_{\mathrm{SL}}$ for each patient was the ratio of performed versus predicted $\mathrm{W}_{\mathrm{SL}}$ times 100 .

The heart volume in the standing position was determined according to the method of Jonsell. ${ }^{16}$ The blood volume was determined with $0.1 \mathrm{MBq}$ iodine 125 . The predicted normal value for men was $71.6 \mathrm{~L}$ times weight in kilograms divided by 1000 , with a standard deviation (SD) of 5.9. For women, the normal value was $62.9 \mathrm{~L}$ times weight $/ 1,000$ (SD 6.4). ${ }^{17,} 18$ The total amount of hemoglobin was calculated from the blood volume and hemoglobin concentration. ${ }^{17}$ The predicted normal value for men was $10.5 \mathrm{gm}$ (SD 1.2) times weight/100 and for women it was $8.2 \mathrm{gm}$ (SD 0.6) times weight/100. ${ }^{18}$

The oxygen uptake was assessed on-line by computerized mass spectrometry of mixed expired air (MGA 2000, Airspec, Kent, England). Samples from the superior vena cava, right atrium and ventricle, pulmonary artery, and aorta were analyzed with a CO-Oximeter system (IL 482, 
Table II. Clinical and anthropometric data in 53 patients at operation and at follow-up 13 to 26 years after repair of tetralogy of Fallot

\begin{tabular}{|c|c|c|c|}
\hline & $\begin{array}{l}\text { Female patients } \\
\quad(n=21)\end{array}$ & $\begin{array}{l}\text { Male patients } \\
\quad(n=32)\end{array}$ & $p$ Value \\
\hline \multicolumn{4}{|l|}{ At repair } \\
\hline Acyanotic (No.) & $0-$ & $5(16 \%)$ & 0.15 \\
\hline Palliative shunt (No.) & $12(57 \%)$ & $16(50 \%)$ & 0.82 \\
\hline Age (yr) & $7(1-27)$ & $7(2-42)$ & 0.81 \\
\hline Weight (kg) & $21(8-71)$ & $21(12-62)$ & 0.94 \\
\hline Body surface area $\left(\mathrm{m}^{2}\right)$ & $0.83(0.70-1.80)$ & $0.80(0.50-1.80)$ & $<0.001$ \\
\hline Oxygen saturation $(\%)^{*}$ & $85(61-99)$ & $82(70-94)$ & 0.78 \\
\hline Hematocrit $(\%)^{*}$ & $59(43-75)$ & $50(39-82)$ & 0.04 \\
\hline \multicolumn{4}{|l|}{ At followmup } \\
\hline Age $(\mathrm{yr})$ & $29(14-45)$ & $27(16-65)$ & 0.80 \\
\hline Weight (kg) & $59(37-82)$ & $77(46-110)$ & $<0.001$ \\
\hline Body surface area $\left(\mathrm{m}^{2}\right)$ & $1.65(1.20-1.90)$ & $1.92(1.51-2.50)$ & $<0.001$ \\
\hline Oxygen saturation (\%) & $98(94-100)$ & $98(96-100)$ & 0.21 \\
\hline Hematocrit $(\%)$ & $38(31-45)$ & $43(36-48)$ & $<0.001$ \\
\hline $\mathrm{W}_{\mathrm{SL}}(\mathrm{W})$ & $120(80-200)$ & $170(90-270)$ & $<0.001$ \\
\hline $\mathrm{W}_{\mathrm{SL}} \%$ & $90(59-152)$ & $84(40-128)$ & 0.12 \\
\hline
\end{tabular}

Median and range (in parentheses) are given for continuous data. $W_{S L}$, symptom-limited work capacity, $W_{S L} \%$, $W_{\text {SL }}$ divided by predicted work capacity $\times 100$. *Patients with a history of cyanosis.

Instrumentation Laboratories, Lexington, Ky.). The predicted basal oxygen consumption was calculated from the equation of Krogh and Benedict-Roth, based on age, sex, height, and weight. ${ }^{19}$

Catheterization. Patients were investigated after premedication with $10 \mathrm{mg}$ diazepam. A double-lumen catheter (Cournand 9F, USCI, Billerica, Mass.) was introduced percutaneously in a cubital vein, and a $1.6 \mathrm{~mm}$ radiopaque Teflon catheter (Habia Company, Stockholm, Sweden) was introduced percutaneously in the brachial artery. Observations in healthy subjects were used as normal values. ${ }^{20}$

During the catheterization, various measurements were made after the patients had cycled in the supine position at an average load of $48 \%$ of $\mathrm{W}_{\mathrm{SL}}(95 \% \mathrm{CL} 45 \%$ to $51 \%)$ for a minimum of 4 minutes. Pressures were recorded with a Micor computerized monitor system (Siemens-Elema AB, Stockholm, Sweden). Cardiac output was determined by the direct Fick principle. The systemic vascular resistance was calculated by subtracting the right atrial pressure from the mean aortic pressure and then dividing by the cardiac index.

The pulmonary vascular resistance was calculated by subtracting the pulmonary capillary wedge pressure from the mean pulmonary artery pressure and then dividing by the cardiac index. The right ventricular outflow tract area was calculated by applying the Gorlin formula. ${ }^{21}$

Echocardiography. Velocities across the right ventricular outflow tract were measured with pulsatile and continuous-wave Doppler technique (Vingmed CFM 750, Horten AS, Norway, with a $3.25 / 2.5 \mathrm{MHz}$ probe, or Acuson XP10, Mountain View, Calif, with a 2.5/2.0 probe) as the maximum velocity in one of several transducer positions. Regurgitation was classified as none, trivial, slight, moderate, or severe and was graded from a synthesis of the color Doppler information, the hemodynamic information in the pulsed Doppler signal, and the spectral intensity in the continuous-wave signal, in the parasternal and apical views. ${ }^{22}$

Statistical methods. Continuous variables were presented as median and range, mean, and SD or $95 \% \mathrm{CL}$. Two samples were compared with the Student $t$ test, the Mann-Whitney U test, or the Wilcoxon test. Analysis of variance or, in the case of skew distributions, the KruskalWallis test was applied to compare three distributions. Analysis of covariance was used to compare regressions. Qualitative data were analyzed with the Fisher exact test. Stepwise regression analysis was applied to relate $\mathrm{W}_{\mathrm{SL}}$ to demographic patient variables, total hemoglobin, heart volume, systolic right ventricular pressure, moderate or severe pulmonary valve incompetence, and use of a transannular patch. The total hemoglobin, used in the regression analysis, does not vary with age and correlates to sex, weight, and physical fitness. ${ }^{18}$ The total hemoglobin had colinearity to body surface area $(r=0.77)$ and basal oxygen consumption $(r=0.76)$, but it and the heart volume were not included in the final regression equation, because these variables did not increase the fraction of explained variance. Natural distribution plots and the Cook D test were applied to evaluate nonlinear relations and the effects of outlying values. Multiple regression was applied to analyze pressures and pressure differences in relation to cardiac output, at rest and during exercise. Deviation of more than two SD from reference mean in healthy subjects was considered abnormal. The null hypothesis was rejected if $p$ was less than 0.05 . Calculations were performed according to Armitage and Berry ${ }^{23}$ and Draper and Smith. ${ }^{24}$

\section{Results}

Clinical and anthropometric data. Fifty (94\%) of the 53 patients were asymptomatic and were taking no medication for cardiovascular disease at the time 
Table III. Clinical data in 53 patients evaluated 13 to 26 years after repair of tetralogy of Fallot in relation to type of right ventricular outflow repair

\begin{tabular}{|c|c|c|c|c|}
\hline & $\begin{array}{l}\text { No patch } \\
(n=21)\end{array}$ & $\begin{array}{l}\text { Right ventricular patch } \\
\qquad(n=18)\end{array}$ & $\begin{array}{l}\text { Transannular patch } \\
(n=14)\end{array}$ & $p$ Value \\
\hline Female patients (No.) & $7(33 \%)$ & $8(44 \%)$ & $6(43 \%)$ & 0.75 \\
\hline Acyanotic before repair (No.) & $5(24 \%)$ & $0-$ & $0-$ & 0.01 \\
\hline Previous palliative shunt (No.) & $5(24 \%)$ & $14(78 \%)$ & $9(64 \%)$ & 0.002 \\
\hline Age $(y r)$ & $33(13)$ & $34(10)$ & $25(7)$ & 0.04 \\
\hline Body surface area $\left(\mathrm{m}^{2}\right)$ & $1.9(0.3)$ & $1.8(0.2)$ & $1.7(0.3)$ & 0.09 \\
\hline Heart volume $\left(\mathrm{ml} / \mathrm{m}^{2} \mathrm{BSA}\right)$ & $448(132)$ & $440(74)$ & $502(143)$ & 0.49 \\
\hline Total hemoglobin (gm) & $700(161)$ & $610(125)$ & $606(114)$ & 0.15 \\
\hline Blood volurne (L) & $5.2(1.1)$ & $4.6(0.7)$ & $4.6(0.6)$ & 0.13 \\
\hline Basal $\mathrm{O}_{2}$ consumption $(\mathrm{ml} / \mathrm{min})$ & $248(49)$ & $223(35)$ & $227(45)$ & 0.27 \\
\hline $\mathrm{W}_{\mathrm{SL}}(\mathrm{W})$ & $173(60)$ & $154(41)$ & $150(27)$ & 0.30 \\
\hline $\mathrm{W}_{\mathrm{SL}} \%$ & $92(23)$ & $90(25)$ & $78(12)$ & 0.21 \\
\hline Heart rate at $W_{S L}$ & $162(26)$ & $166(15)$ & $166(14)$ & 0.77 \\
\hline
\end{tabular}

Mean and SD (in parentheses) are given for continuous data. $B S A$, body surface area; $W_{S L}$, symptom-limited work capacity; $W_{S L} \%, \mathrm{~W}_{\mathrm{SL}}$ divided by predicted work capacity $\times 100$

of follow-up. One patient was being treated for hypertension and one for supraventricular arrhythmia. One patient had a residual ventricular septal defect, symptoms of congestive heart failure, and pacemaker treatment because of episodes of tachyarrhythmia.

A wide span of ages and large differences in body size existed among male and female patients at the time of repair and at follow-up (Table II). Patients in whom a transannular patch had been inserted were younger at follow-up than either those without a patch or those with a right ventricular patch (Table III). Patients without a patch less frequently had a palliative shunt and tended to have a larger body surface area, a higher total hemoglobin value, a larger blood volume, and a higher predicted basal oxygen consumption than those with a patch.

Exercise capacity. The mean $\mathrm{W}_{\mathrm{SL}}$ in 50 of 53 patients $(94 \%)$ was $161 \mathrm{~W}$ (95\% CL 147 to $194 \mathrm{~W}$ ), corresponding to $87 \%(95 \% \mathrm{CL} 82 \%$ to $94 \%$ ) of the predicted value. $\mathrm{W}_{\mathrm{SL}}$ was reduced by $8 \%$ in the patients without a transannular patch, compared with $22 \%$ in the patients with a transannular patch (see Table III). Dyspnea limited 35 patients (70\%) at a median Borg score of 6 (range 6 to 9) on a scale of 10 . General or leg fatigue limited the remaining 15 patients at a median Borg score of 7 (range 6 to 9).

$\mathrm{W}_{\mathrm{SL}}$ was high in young patients and in male patients and correlated significantly to age, sex, right ventricular systolic pressure at rest, and pulmonary valve incompetence (Fig. 1, Table IV). The predicted $\mathrm{W}_{\mathrm{SL}}$ was, on the average, $47 \mathrm{~W}$ higher in male patients and was reduced by $17 \mathrm{~W}$ for every 10 -year
Table IV. Stepwise regression analysis of symptomlimited work capacity in 50 patients evaluated 13 to 26 years after repair of tetralogy of Fallot in relation to sex, age, right ventricular systolic pressure, moderate or severe pulmonary valve incompetence at follow-up, and use of transannular patch at repair*

\begin{tabular}{|c|c|c|c|c|}
\hline $\begin{array}{l}\text { Independent } \\
\text { variables }\end{array}$ & $\begin{array}{l}\text { Regression } \\
\text { coefficient }\end{array}$ & $S D$ & $\begin{array}{c}\text { Probability } \\
\text { of effect }\end{array}$ & \\
\hline Sex & 47.3 & 12.0 & $p<0.001$ & \\
\hline $\begin{array}{l}\text { Age at follow-up } \\
\text { (years) }\end{array}$ & -1.7 & 0.5 & $p<0.001$ & \\
\hline $\begin{array}{l}\text { RV systolic pressure } \\
\text { (mm Hg) }\end{array}$ & -1.1 & 0.3 & $p=0.002$ & \\
\hline $\begin{array}{l}\text { Pulmonary valve } \\
\text { incompetence }\end{array}$ & -24.5 & 12.2 & $p=0.05$ & \\
\hline Transannular patch & -19.6 & 12.4 & $p=0.12$ & $\mathrm{R}_{\mathrm{adj}}=0.61$ \\
\hline
\end{tabular}

$R_{a d ;}$ Adjusted R-squared, fraction of explained variance; $R V$, right ventricle.

*Dependent variable: symptom-limited work capacity.

increment of age and by $11 \mathrm{~W}$ for every $10 \mathrm{~mm} \mathrm{Hg}$ increase in the right ventricular systolic pressure at rest. The presence of moderate or severe pulmonary valve incompetence reduced $\mathrm{W}_{\mathrm{SL}}$. The use of a transannular patch had a negative but not significant influence on the $\mathrm{W}_{\mathrm{SL}}$.

Central hemodynamics at rest and during supine exercise. Twenty-three $(50 \%)$ of 46 patients who exercised during the catheterization were normokinetic at rest, with an arteriovenous oxygen difference ranging from 35 to $45 \mathrm{ml} / \mathrm{L}$. The remaining 23 patients were hypokinetic at rest, with an arteriovenous oxygen difference higher than $45 \mathrm{ml} / \mathrm{L}$. During exercise, 34 patients (74\%) were hypokinetic, 


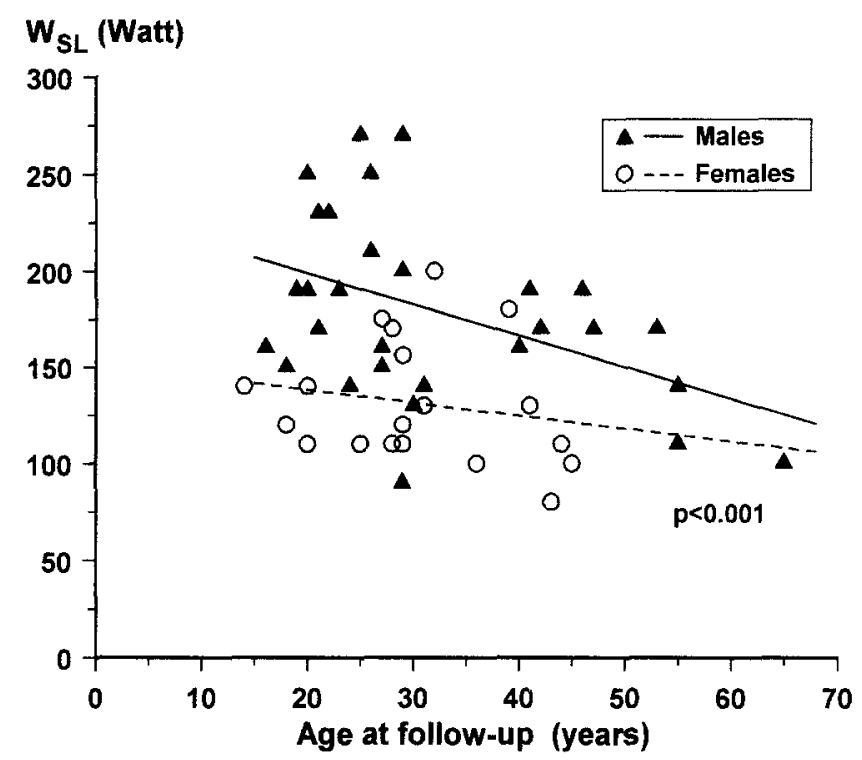

Fig. 1. Symptom-limited work capacity $\left(W_{S L}\right)$ in patients evaluated 13 to 26 years after repair of tetralogy of Fallot in relation to age at follow-up and sex. Regression lines are indicated.

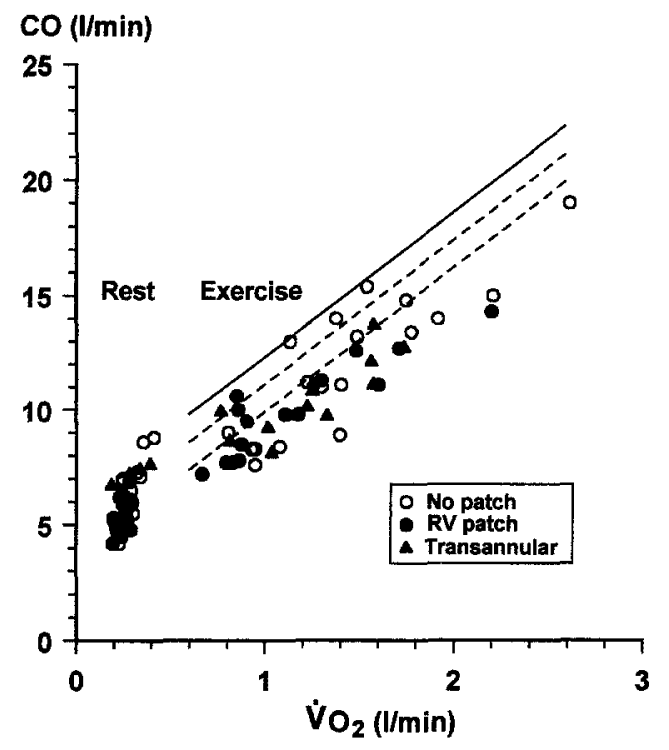

Fig. 2. Cardiac output ( $C O$ ) in relation to oxygen uptake $\left(\dot{V}_{2}\right)$ at rest and during supine exercise 13 to 26 years after repair of tetralogy of Fallot. Type of reconstruction of the right ventricle $(R V)$ is indicated. Mean regression lines for healthy subjects within minus one and minus two SD during exercise are shown. ${ }^{20}$

with a reduced cardiac output in relation to the oxygen uptake (Fig. 2).

The cardiac output at rest was high in patients without a patch and tended to be high also during

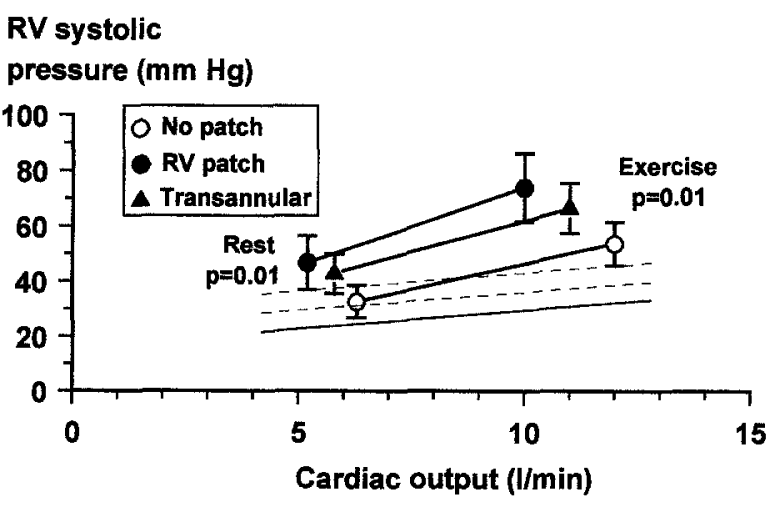

Fig. 3. Systolic pressure in the right ventricle $(R V)$ at rest and during exercise (mean with $95 \% \mathrm{CL}$ ) in relation to mean cardiac output in the groups without a patch, with an RV patch, and with a transannular patch, 13 to 26 years after repair of tetralogy of Fallot. Mean regression lines for healthy subjects within one and two SD are indicated. $^{20}$

exercise, compared with the output in those with a patch (Table V). The stroke volume, arteriovenous oxygen difference, and oxygen uptake did not differ significantly between the groups at rest or during exercise (see Table V).

The systolic pressure in the right ventricle, related to cardiac output, was low at rest and during exercise in patients without a patch compared with those with a patch. It was elevated in all groups during exercise, as 
Table V. Hemodynamic findings at rest and during exercise in relation to type of surgical repair of the right ventricular outflow in 46 patients examined 13 to 26 years after repair of tetralogy of Fallot

\begin{tabular}{|c|c|c|c|c|c|c|c|c|}
\hline & \multicolumn{3}{|c|}{ At rest } & \multicolumn{4}{|c|}{ During exercise } & \multirow[b]{2}{*}{$\begin{array}{c}p \\
\text { Value }\end{array}$} \\
\hline & $\begin{array}{c}\text { No } \\
\text { patch } \\
(n=19)\end{array}$ & $\begin{array}{c}\text { Right } \\
\text { ventricular } \\
\text { patch } \\
(n=15)\end{array}$ & $\begin{array}{c}\text { Transannular } \\
\text { patch } \\
(n=12)\end{array}$ & $\begin{array}{c}p \\
\text { Value }\end{array}$ & $\begin{array}{l}\text { No patch } \\
(n=19)\end{array}$ & $\begin{array}{c}\text { Right } \\
\text { ventricular } \\
\text { patch } \\
(n=15)\end{array}$ & $\begin{array}{c}\text { Transannular } \\
\text { patch } \\
(n=12)\end{array}$ & \\
\hline Work in supine position (W) & - & - & - & - & $86(37)$ & $73(35)$ & $75(20)$ & 0.46 \\
\hline Cardiac output $(\mathrm{L} / \mathrm{min})$ & $6.3(1.2)$ & $5.2(0.8)$ & $5.8(1.2)$ & 0.02 & $12.0(3.0)$ & $10.0(2.1)$ & $11.0(1.7)$ & 0.10 \\
\hline Stroke volume $(\mathrm{ml})$ & $91(19)$ & $80(11)$ & $83(23)$ & 0.28 & $102(20)$ & $90(12)$ & $91(16)$ & 0.08 \\
\hline Arteriovenous $\mathrm{O}_{2}$ difference $(\mathrm{ml})$ & $44(6)$ & $47(7)$ & $46(8)$ & 0.46 & $117(23)$ & $112(21)$ & $119(19)$ & 0.65 \\
\hline Oxygen uptake (ml/min) & $277(53)$ & $239(29)$ & $261(53)$ & 0.09 & $1436(478)$ & $1148(423)$ & $1262(313)$ & 0.16 \\
\hline
\end{tabular}

Values given are mean and SD (in parentheses).

Table VI. Central hemodynamics at rest and during exercise in relation to type of surgical repair of the right ventricular outflow in 46 patients examined 13 to 26 years after repair for tetralogy of Fallot

\begin{tabular}{|c|c|c|c|c|c|c|c|c|}
\hline & \multicolumn{3}{|c|}{ Rest } & \multicolumn{4}{|c|}{ Exercise } & \multirow[b]{2}{*}{$\begin{array}{c}p \\
\text { Value } \\
\end{array}$} \\
\hline & $\begin{array}{l}\text { No patch } \\
(n=19)\end{array}$ & $\begin{array}{c}\text { Right } \\
\text { ventricular } \\
\text { patch } \\
(n=15)\end{array}$ & $\begin{array}{c}\text { Transannular } \\
\text { patch } \\
(n=12)\end{array}$ & $\begin{array}{c}p \\
\text { Value }\end{array}$ & $\begin{array}{l}\text { No patch } \\
(n=19)\end{array}$ & $\begin{array}{c}\text { Right } \\
\text { ventricular } \\
\text { patch } \\
(n=15)\end{array}$ & $\begin{array}{c}\text { Transannular } \\
\text { patch } \\
(n=12)\end{array}$ & \\
\hline \multicolumn{9}{|l|}{ Pressures (mm Hg) } \\
\hline Right ventricle systolic & $31(16-69)$ & $43(26-85)$ & $40(27-65)$ & 0.02 & $51(27-90)$ & $70(45-110)$ & $70(45-85)$ & 0.01 \\
\hline Right ventricle diastolic & $7(1-17)$ & $8(3-18)$ & $8(6-15)$ & 0.52 & $11(1-28)$ & $13(8-22)$ & $13(7-17)$ & 0.22 \\
\hline $\begin{array}{l}\text { Right ventricular outflow } \\
\text { pressure difference }\end{array}$ & $10(0-31)$ & $12(4-60)$ & $15(0-40)$ & 0.09 & $15(0-35)$ & $30(5-85)$ & $29(0-40)$ & 0.03 \\
\hline Pulmonary artery systolic & $23(5)$ & $25(7)$ & $26(3)$ & 0.41 & $38(10)$ & $40(9)$ & $41(10)$ & 0.69 \\
\hline Pulmonary artery diastolic & $9(3)$ & $8(2)$ & $8(2)$ & 0.11 & $15(4)$ & $12(4)$ & $11(2)$ & 0.01 \\
\hline Pulmonary capillary wedge & $9(4)$ & $9(3)$ & $9(2)$ & 0.95 & $14(4)$ & $15(4)$ & $14(4)$ & 0.61 \\
\hline Aorta systolic & $122(17)$ & $124(19)$ & $118(10)$ & 0.36 & $153(17)$ & $155(19)$ & $140(15)$ & 0.06 \\
\hline Aorta diastolic & $74(8)$ & $75(9)$ & $77(9)$ & 0.86 & $84(9)$ & $87(12)$ & $84(8)$ & 0.59 \\
\hline \multicolumn{9}{|l|}{ Outflow area $\left(\mathrm{cm}^{2}\right)$} \\
\hline Right ventricle & $2.53(0.63)$ & $1.71(0.73)$ & $1.56(0.69)$ & 0.005 & $2.68(0.53)$ & $1.47(0.54)$ & $1.86(0.80)$ & 0.002 \\
\hline Right ventricle* & $2.14(0.79)$ & $1.80(0.80)$ & $1.43(0.40)$ & 0.28 & $2.45(0.69)$ & $1.36(0.53)$ & $1.63(0.71)$ & 0.007 \\
\hline \multicolumn{9}{|l|}{$\begin{array}{l}\text { Vascular resistance } \\
\qquad\left(\mathrm{mm} \mathrm{Hg} \mathrm{L} \mathrm{H}^{-1} \cdot \min \cdot \mathrm{m}^{2}\right)\end{array}$} \\
\hline Systemic $\dagger$ & $28(7)$ & $32(6)$ & $26(6)$ & 0.09 & $16(2)$ & $20(4)$ & $17(3)$ & 0.03 \\
\hline Pulmonary & $1.6(0.8)$ & $1.9(0.6)$ & $1.6(0.5)$ & 0.34 & $1.6(0.9)$ & $1.9(0.7)$ & $1.8(0.8)$ & 0.77 \\
\hline
\end{tabular}

Values given are mean and SD (in parentheses); values for right ventricular measures are median and range (in parentheses).

*Area calculated disregarding patients with moderate or severe pulmonary valve incompetence.

$\dagger$ Reference mean, rest 26.6 ; SD $5.6 \mathrm{~mm} \mathrm{Hg} \mathrm{L}-1 \cdot \min \cdot \mathrm{m}^{2}$.

$\ddagger$ Normal, rest $<3.1 \mathrm{~mm} \mathrm{Hg} \mathrm{L}{ }^{-1} \cdot \min \cdot \mathrm{m}^{2}$.

compared with healthy individuals (Fig. 3, Table VI). The $\mathrm{W}_{\mathrm{SL}}$ was inversely related to the systolic pressure in the right ventricle at rest (Fig. 4). Patients with 50 $\mathrm{mm} \mathrm{Hg}$ or higher systolic pressure in the right ventricle could not reach a workload of $200 \mathrm{~W}$.

The diastolic pressure in the right ventricle did not differ significantly between the groups. It increased slightly during exercise and was elevated in all groups compared with healthy individuals (see Table VI). The median peak systolic pressure difference at the right ventricular outflow was $77 \mathrm{~mm}$
$\mathrm{Hg}$ (range 42 to $103 \mathrm{~mm} \mathrm{Hg}$ ) before repair and was reduced to $15 \mathrm{~mm} \mathrm{Hg}$ (range 0 to $46 \mathrm{~mm} \mathrm{Hg}$ ) immediately after repair $(p<0.001)$. At follow-up, the median pressure difference at rest was $12 \mathrm{~mm}$ $\mathrm{Hg}$ (range 0 to $60 \mathrm{~mm} \mathrm{Hg}$ ). It increased to $20 \mathrm{~mm}$ $\mathrm{Hg}$ (range 0 to $85 \mathrm{~mm} \mathrm{Hg}$ ) during exercise $(p<$ $0.001)$ and was higher in patients with a patch than in those without a patch (see Table VI).

The pressure difference across the right ventricular outflow, in relation to cardiac output, at rest and during exercise, was higher in patients with an 


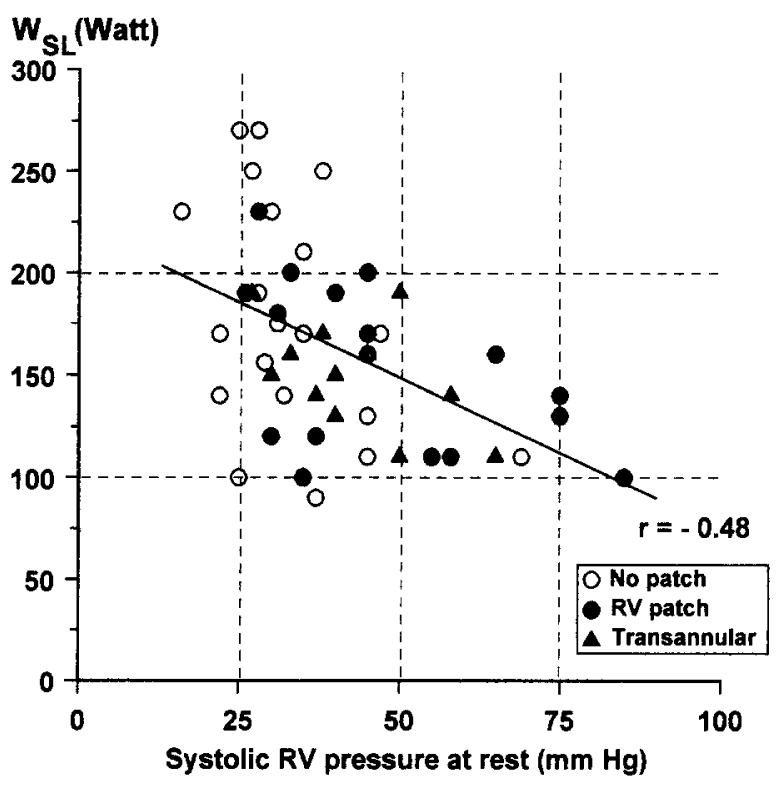

Fig. 4. Symptom-limited work capacity $\left(W_{S L}\right)$ in relation to systolic pressure in the right ventricle $(R V)$ at rest, 13 to 26 years after repair of tetralogy of Fallot. Type of reconstruction of the RV and regression line are indicated.

outflow patch than in healthy individuals (Fig. 5). At follow-up, right ventricular outflow pressures of more than $50 \mathrm{~mm} \mathrm{Hg}$ at rest or during exercise were recorded in five patients with a right ventricular patch (Fig. 6). After follow-up evaluation, one patient with recurrent pulmonary valvular stenosis had a successful percutaneous valvuloplasty, and a second patient received a homograft valve in the right ventricular outflow at reoperation.

Pulmonary valve regurgitation and right ventricular outflow area also were evaluated. The right ventricular outflow area was larger in patients without an outflow patch, at rest and during exercise, than in those with a patch (see Table VI). Doppler echocardiography in 51 patients showed moderate or severe pulmonary valve incompetence in 16 patients $(31 \%)$. Such regurgitation was present in 8 $(57 \%)$ of 14 patients with a transannular patch, compared with $3(15 \%)$ of 20 without a patch and 5 $(27 \%)$ of 17 with a right ventricular patch $(p=0.03)$. The outflow area was still large, if calculated by excluding patients with a large total right ventricular stroke volume caused by significant pulmonary valve incompetence and including only those with less than moderate valve incompetence (see Table VI).

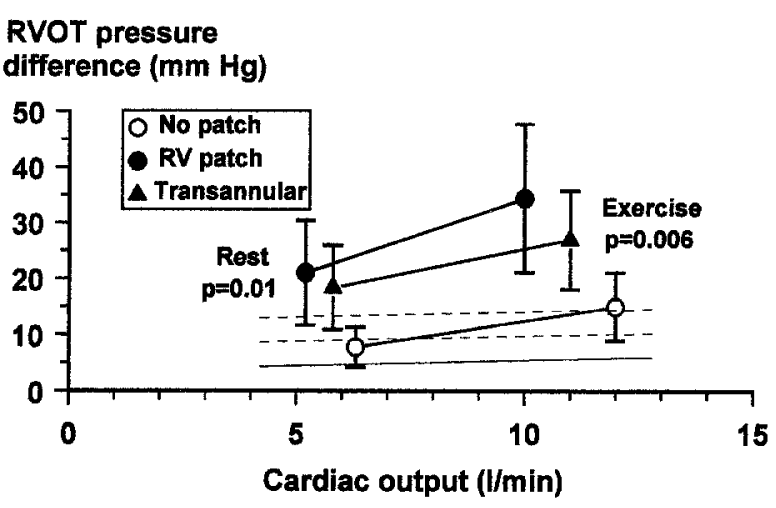

Fig. 5. Right ventricular outflow tract (RVOT) pressure difference (mean with $95 \% \mathrm{CL}$ ), at rest and during exercise, in relation to mean cardiac output in the groups without a patch, with an RV patch, and with a transannular patch, 13 to 26 years after repair of tetralogy of Fallot. Mean regression lines for healthy subjects within one and two SD are indicated. ${ }^{20}$

The median RV/LV systolic pressure ratio immediately after repair was 0.51 (range 0.24 to 1.04 ), a significantly higher level $(p<0.001)$ than at followup, which was 0.30 (range 0.15 to 0.71 ). The pressure ratio at rest increased significantly $(p<0.001)$ to 0.40 (range 0.20 to 0.81 ) during exercise (Fig. 7). Ten long-term survivors $(19 \%)$ had an immediate postrepair RV/LV pressure ratio of 0.80 or higher that had fallen to less than 0.55 by the time of follow-up. In one patient without a patch, widening was not possible because of a large coronary artery that crossed the right ventricular outflow tract. Despite widening with a transannular patch, five patients had a postrepair $\mathrm{RV} / \mathrm{LV}$ pressure ratio higher than 0.80 . In two of the latter, the patch extended onto the left pulmonary artery. In four of these five patients, angiography had demonstrated hypoplasia or stenosis of pulmonary artery branches.

The systemic and pulmonary vascular resistances at rest and during exercise were within normal limits (see Table VI). The diastolic pressures in the pulmonary artery during exercise were higher in patients without an outflow patch. The systolic pressures in the pulmonary artery and the aorta and pulmonary capillary wedge pressures did not differ significantly among the three groups. No pressure differences were recorded between the left ventricle and the aorta.

A residual left-to-right shunt was present in six patients $(11 \%)$. Five $(9 \%)$ had a small leak at the ventricular septal patch. One patient with a shunt at 


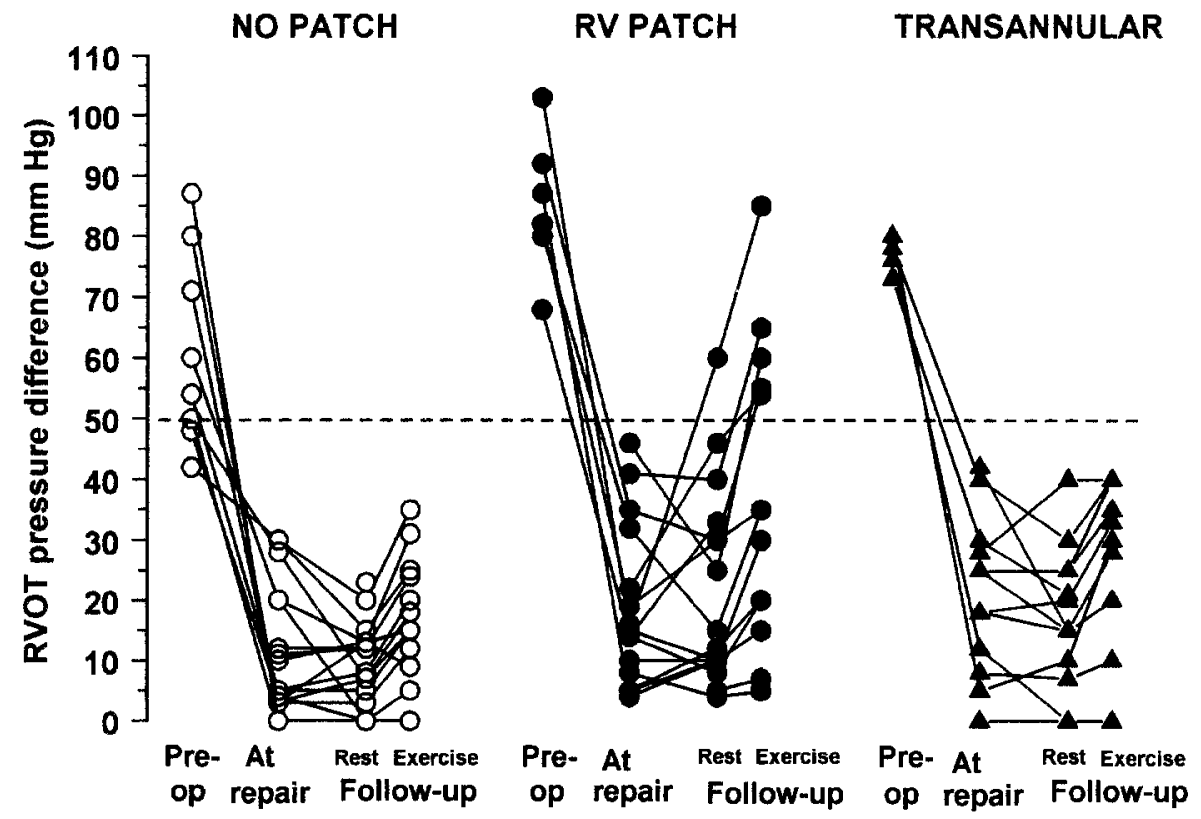

Fig. 6. Right ventricular outflow tract (RVOT) pressure difference before the operation, in the operating room, and at follow-up 13 to 26 years after repair of tetralogy of Fallot at rest and during exercise. Pressures above dotted line at follow-up led to consideration for repeated intervention.

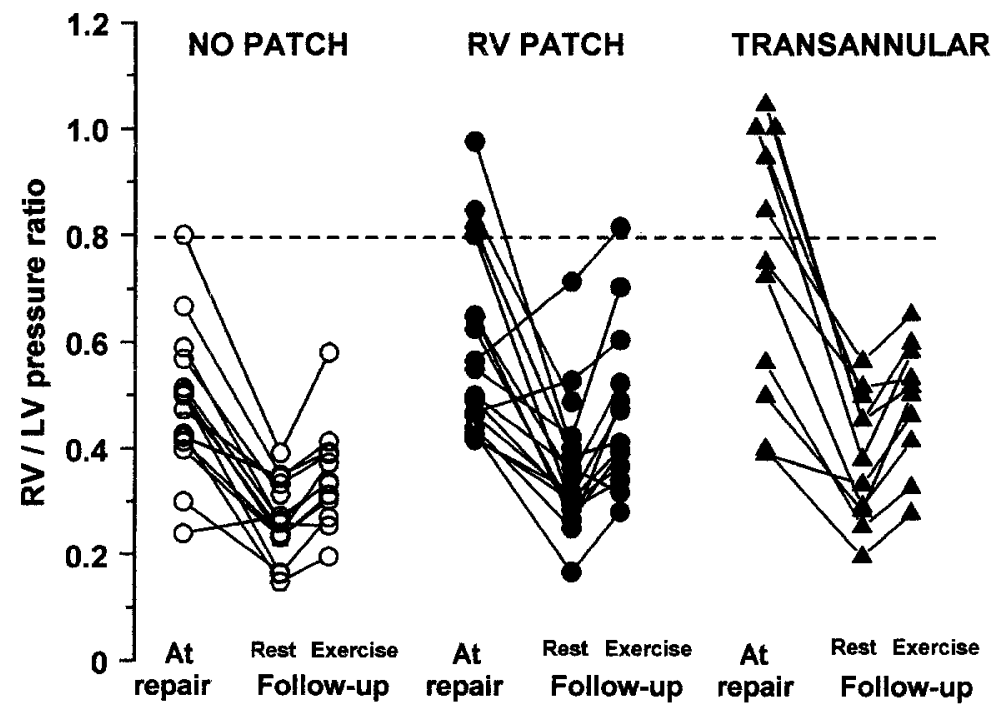

Fig. 7. Right ventricular/left ventricular $(R V / L V)$ pressure ratio in the operating room and at follow-up 13 to 26 years after repair of tetralogy of Fallot at rest and during exercise. A postrepair ratio above dotted line indicates an unfavorable surgical result.

the atrial level, a systemic/pulmonary artery flow ratio of $2: 1$, and an arterial oxygen saturation level of $90 \%$ during exercise underwent subsequent reoperation.

\section{Discussion}

Patients with tetralogy of Fallot included in this report were managed during an early period when the preferred strategy at this clinic was to delay 
intracardiac repair until the patient reached preschool age. The risks associated with cardiopulmonary bypass in infants were high, and palliative shunts inserted in $62 \%$ of the patients offered effective alleviation of cyanosis. Despite elective two-stage repair, the early mortality rate was high $(15 \%)$. One contributory factor may have been the use of intermittent ischemic arrest; cold cardioplegia for myocardial protection had not yet become routine.

The hemodynamic conditions of the studied patients probably reflect those of the entire group of survivors, because clinical data were similar in those who consented to catheterization and those who were not evaluated. The long-term survivors were classified according to type of right ventricular outflow reconstruction. The groups encompassed a spectrum of various morphologic subsets.

Patients without a patch generally had a right ventricle and pulmonary anulus of normal size at repair. The five acyanotic patients had repair without a patch. Patients without a patch were in good physical condition at follow-up, as indicated by the relatively large body surface area and high work capacity. The right ventricular outflow area was large with low pressure differences at follow-up. The high diastolic pressures in the pulmonary artery during exercise, compared with those of patients with a transannular patch, reflect competence of the pulmonary valve.

In the right ventricular patch group, the strategy at operation was to leave the pulmonary anulus intact. This was not always an optimal decision, because four patients had a postrepair RV/LV pressure ratio of 0.80 or higher. Only in this group did we record systolic pressure differences at the right ventricular outflow that exceeded $50 \mathrm{~mm} \mathrm{Hg}$ during exercise.

Use of a transannular patch implied that the pulmonary anulus or main pulmonary artery was either small or atretic. Despite the frequent use of palliative shunts, these patients required intracardiac repair at a young age and were younger at follow-up, with smaller body surface area and lower work capacity than patients without a patch. Notwithstanding the extension of the patch across the pulmonary anulus, five patients had a postrepair $\mathrm{RV} / \mathrm{LV}$ pressure ratio of 0.80 or higher.

The tendency in patients with a transannular patch to have a large heart volume reflects a dilated right ventricle caused by pulmonary valve regurgitation. In several reports, a large heart after repair has been associated with the presence of pulmonary valve incompetence and a poor clinical result. $^{2,4,9,25,26}$ All methods that widen the pulmonary anulus may cause pulmonary valve regurgitation. The regurgitation increases the stroke volume and the entire volume load of the right ventricle. If pulmonary valve incompetence is not severe, it is well tolerated, unless there is distal obstruction of the pulmonary artery or its branches or elevated left ventricular filling pressure. ${ }^{5}$ Long-standing severe pulmonary valve incompetence is poorly tolerated by the right ventricle and predisposes to arrhythmias as well as to right and left ventricular dysfunction. $9,11,25$

Work capacity was reduced by an average of $13 \%$ and was inversely related to age. Hirschfeld and colleagues $^{27}$ found that the reduced work capacity was independent of age at repair, length of followup, previous palliative shunt, and the use of an outflow patch. Observations of other authors agree with our finding of a diminished work capacity associated with the use of a transannular patch. ${ }^{25,26}$ In contrast to our findings, Joransen, Lucas, and Moller ${ }^{7}$ found a normal cardiac output in relation to oxygen uptake during exercise in $89 \%$ of the patients.

$\mathrm{W}_{\mathrm{SL}}$ was adversely influenced by a high right ventricular systolic pressure and by pulmonary valve incompetence, in agreement with the findings at other centers. ${ }^{26,28} \mathrm{We}$ assume that a high systolic pressure in the right ventricle at rest reflects the detrimental effect of chronic stress. Suggested factors contributing to a reduced work capacity include older age at repair, severe preoperative hypoxemia, small size of the left ventricle, myocardial fibrosis, long-standing abnormal right ventricular pressure or volume load, and alteration of the contracting right ventricular wall and septum as a result of stenting by outflow and septal patches. $8,25,27,29-31$ In healthy subjects, the diastolic pressure in the right ventricle slowly decreases during exercise, whereas we observed an increase, indicating an impaired diastolic function. ${ }^{17}$

Several reports have confirmed that high postrepair $\mathrm{RV} / \mathrm{LV}$ pressure ratios predict poor early and late outcomes. ${ }^{2,4,7,10,13,29,31-35}$ The RV/LV pressure ratio not only reflects residual outflow obstruction but also depends on right ventricular function and factors influencing left ventricular impedance to flow, such as elastic and restrictive myocardial properties, valve function, systemic arterial pressure, and vascular resistance. Thus transient postoperative failure of the left ventricle increases the RV/LV pressure ratio. 
The RV/LV pressure ratio measured in the operating room can be expected to fall in many patients during the first hours after repair., $33,34,36,37$ In our patients, the postrepair RV/LV ratio was significantly reduced at follow-up. Particularly in the longterm survivors with a postrepair ratio exceeding 0.80 , the systolic pressure in the right ventricle must have fallen early during the postoperative course.

Three of our patients required reoperation before follow-up, and in three further patients we intervened as a result of the findings at follow-up. The timing of the reoperation is sometimes difficult in these often young, symptom-free, fully employed patients who are reluctant to undergo further surgery. Several authors recommend that reoperation should be undertaken in asymptomatic patients if the systolic pressure at rest in the right ventricle is higher than $50 \mathrm{~mm} \mathrm{Hg}$ or if outflow pressure difference exceeds $40 \mathrm{~mm} \mathrm{Hg.}{ }^{1,4,7}$ Ilbawi and coworkers ${ }^{11}$ successfully inserted pulmonary valves in 42 of 48 patients with right ventricular dysfunction associated with distal pulmonary stenosis, moderate pulmonary regurgitation, and a transannular outflow patch.

We conclude that work capacity is moderately reduced 13 to 26 years after surgical repair of tetralogy of Fallot. A high work capacity was predicted from male sex, young age, low right ventricular systolic pressure, and an absence of pulmonary valve regurgitation. Patients without an outflow patch had low systolic pressure in the right ventricle and a large right ventricular outflow area, compared with those who had a patch. RV/LV pressure ratios were markeclly reduced in all groups, compared with postrepair measurements. High systolic pressure in the right ventricle was observed in symptom-free patients with a right ventricular patch, and it necessitated intervention in three of them. After intracardiac repair of tetralogy of Fallot, the patient should have intermittent lifelong medical surveillance, regardless of the cardiac symptoms.

We acknowledge statistical advice and calculations performed by Ulf Brodin, MSc in Medical Statistics, Karolinska Institute, Stockholm, Sweden.

\section{REFERENCES}

1. Calza G, Panizzon G, Rovida S, Aigueperse J. Incidence of residual defects determining the clinical outcome after correction of tetralogy of Fallot: postoperative late follow-up. Ann Thorac Surg 1989;47: 428-35.
2. Fuster V, McGoon DC, Kennedy MA, Ritter DG, Kirklin JW. Long-term evaluation (12 to 22 years) of open heart surgery for tetralogy of Fallot. Am J Cardiol 1980;46:635-42.

3. John S, Kejriwal NK, Ravikumar E, Bashi VV, Mohanty BB, Sukumar IJ. The clinical profile and surgical treatment of tetralogy of Fallot in the adult: results of repair in 200 patients. Ann Thorac Surg 1986;41: 502-6.

4. Poirer RA, McGoon DC, Danielson GK, et al. Late results after repair of tetralogy of Fallot. J THORAC CARDIOVASC SURG 1977;73:900-8.

5. Ruzyllo W, Nihill MR, Mullins CE, McNamara DG. Hemodynamics evaluation of 221 patients after intracardiac repair of tetralogy of Fallot. Am J Cardiol 1974;34:565-76.

6. Chen D, Moller JH. Comparison of late clinical status between patients with different hemodynamic findings after repair of tetralogy of Fallot. Am Heart J 1987; 113:767-72.

7. Joransen JA, Lucas RV, Moller JH. Postoperative haemodynamics in tetralogy of Fallot: a study of 132 children. Br Heart J 1979;41:33-9.

8. Murphy JD, Freed MD, Keane JF, Norwood WI, Castaneda AR, Nadas AS. Hemodynamics results after intracardiac repair of tetralogy of Fallot by deep hypothermia and cardiopulmonary bypass. Circulation 1980;62(Suppl I):168-74.

9. Rosing DR, Borer JS, Kent KM, et al. Long-term hemodynamic and electrocardiographic assessment following operative repair of tetralogy of Fallot. Circulation 1978;58(Suppl I):209-17.

10. Rizzoli G, Mazzucco A, Fracasso A, Stellin G, Rubino M, Gallucci V. Early and late results after repair of tetralogy of Fallot. Eur J Cardiothorac Surg 1990;4: 371-8.

11. Ilbawi MN, Idriss FS, DeLeon SY, et al. Factors that exaggerate the deleterious effects of pulmonary insufficiency on the right ventricle after tetralogy repair: surgical implications. J THORAC CARDIOVASC SURG 1987;93:36-44.

12. Rocchini AP, Roenthal A, Freed M, Castaneda AR, Nadas AS. Chronic congestive heart failure after repair of tetralogy of Fallot. Circulation 1977;56:305-10.

13. Abril E, Björk VO, Ivert T, Olin C. Reconstruction of the right ventricular outflow tract in patients with tetralogy of Fallot: early and late results. Scand J Thorac Cardiovase Surg 1982;16:33-40.

14. Borg G, Holmgren A, Lindblad I. Perception of pain in the chest during physical work in a group of patients with angina pectoris. Reports from the Institute of Applied Psychology, University of Stockholm 1979;81:1-10.

15. Nordenfelt I, Adolfsson L, Nilsson JE, Olsson S. Reference values for exercise tests with continuous increase in load. Clin Physiol 1985;5:161-72. 
16. Jonsell S. A method for the determination of the heart size by the teleroentgenography (a heart volume index). Acta Radiol 1939;20:325-40.

17. Gregersen MJ, Rawson RA. Blood volume. Physiol Rev 1959;39:307.

18. Strandell T. Total haemoglobin, blood volume and haemoglobin concentration at rest and circulatory adaptation during exercise in relation to some anthropometric data in old men compared with young men. Acta Med Scand 1964;176:219-32.

19. Harris JA, Benedict FG. Biometric study of basal metabolism in man. Carnegie Institute Washington, 1919. Publ. 279.

20. Eklund LG, Holmgren A. Central hemodynamics during exercise. Circ Res 1967;20-21(suppl I):33-43.

21. Gorlin R, Gorlin SG. Hydraulic formula for calculation of the area of the stenotic valve, other cardiac valves and central circulatory shunts. Am Heart J 1951;41:1-29.

22. Feigenbaum $H$. Hemodynamic information derived from echocardiography. In: Feigenbaum H. Echocardiography. 5th ed. Philadelphia: Lea \& Febiger, 1994: 181-210.

23. Armitage P, Berry G. Statistical methods in medical research. 2nd ed. Oxford: Blackwell Scientific, 1987.

24. Draper NR, Smith H. Applied regression analysis. New York: John Wiley: 1981.

25. Vetter HO, Reichart B, Seidel P, Kleinhans E, Büll U, Klinner W. Non-invasive assessment of right and left ventricular volumes 11-24 years after corrective surgery on patients with tetralogy of Fallot. Eur J Cardiothorac Surg 1990;4:24-8.

26. Wessel HU, Cunningham WJ, Paul MH, Bastanier CK, Muster AJ, Idriss FS. Exercise performance in tetralogy of Fallot after intracardiac repair. J THORAC Cardiovasc Surg 1980;80:582-93.

27. Hirschfeld S, Tuboku-Metzger AJ, Borkat G, Ankeney J, Clayman J, Liebman J. Comparison of exercise and catheterization results following total surgical correlation of tetralogy of Fallot. J THORAC CARDIOVASC SURG 1978; 75:446-51.
28. Carvalho JS, Shinebourne EA, Busst C, Rigby ML, Redington AN. Exercise capacity after complete repair of tetralogy of Fallot: deleterious effects of residual pulmonary regurgitation. Br Heart J 1992;67:470-3.

29. Hausdorf G, Hinrichs C, Nienaber CA, Schark C, Keck EW. Left ventricular contractile state after surgical correction of tetralogy of Fallot: risk factors for late left ventricular dysfunction. Pediatr Cardiol 1990;11:61-8.

30. Bastos P, Campos J, Cunha D, Gomes M. Left ventricular function after total correction of tetralogy of Fallot. Eur Heart J 1991;12:1089-97.

31. Borow KM, Green LH, Castaneda AR, Keane JF. Left ventricular function after repair of tetralogy of Fallot and its relationship to age at surgery. Circulation 1990;61:1150-8.

32. Hamilton DI, Di Eusanio G, Piccoli GP, Dickinson DF. Eight years' experience with intracardiac repair of tetralogy of Fallot: early and late results in 175 consecutive patients. Br Heart J 1981;46:144-51.

33. Kirklin JW, Blackstone EH, Pacifico AD, Kirklin JK, Bargeron LM. Risk factors for early and late failure after repair of tetralogy of Fallot and their neutralization. Thorac Cardiovasc Surg 1984;32:208-14.

34. Kirklin JW, Blackstone EH, Jonas RA, et al. Morphologic and surgical determinants of outcome events after repair of tetralogy of Fallot and pulmonary stenosis: a two-institutional study. J THORAC CARDIOVASC SURG 1992;103:706-23.

35. Murphy JG, Gersh BJ, Mair DD, et al. Long-term outcome in patients undergoing surgical repair of tetralogy of Fallot. N Engl J Med 1993;329:593-9.

36. Bertranou EG, Thibert M. Short-term variations of the right ventricular/left ventricular pressure rato following repair of tetralogy of Fallot. Ann Thorac Surg 1983;35:427-9.

37. Lang P, Chipman CW, Siden H, Williams RG, Norwood WI, Castaneda AR. Early assessment of hemodynamic status after repair of tetralogy of Fallot: a comparison of 24 hour (intensive care unit) and 1 year postoperative data in 98 patients. Am J Cardiol 1982;50:795-9. 